\title{
Dispersion Tolerance of 40 Gbaud Multilevel Modulation Formats with up to 3 bits per Symbol
}

Jensen, Jesper Bevensee; Tokle, Torger; Geng, Yan; Jeppesen, Palle; Serbay, M.; Rosenkranz, W.

Published in:

IEEE Lasers and Electro-Optics Society Annual Meeting

Link to article, DOI:

10.1109/LEOS.2006.278735

Publication date:

2006

Document Version

Publisher's PDF, also known as Version of record

Link back to DTU Orbit

Citation (APA):

Jensen, J. B., Tokle, T., Geng, Y., Jeppesen, P., Serbay, M., \& Rosenkranz, W. (2006). Dispersion Tolerance of 40 Gbaud Multilevel Modulation Formats with up to 3 bits per Symbol. In IEEE Lasers and Electro-Optics Society Annual Meeting (pp. WH4). IEEE. https://doi.org/10.1109/LEOS.2006.278735

\section{General rights}

Copyright and moral rights for the publications made accessible in the public portal are retained by the authors and/or other copyright owners and it is a condition of accessing publications that users recognise and abide by the legal requirements associated with these rights.

- Users may download and print one copy of any publication from the public portal for the purpose of private study or research.

- You may not further distribute the material or use it for any profit-making activity or commercial gain

- You may freely distribute the URL identifying the publication in the public portal 


\title{
Dispersion Tolerance of 40 Gbaud Multilevel Modulation Formats with up to 3 bits per Symbol
}

\author{
Jesper Bevensee Jensen, Torger Tokle, \\ Yan Geng and Palle Jeppesen, \\ COM•DTU Department of Communication, Optics and Materials, \\ Technical University of Denmark \\ Ørsteds Plads, Building 345V, DK-2800 Kgs. Lyngby, Denmark \\ Email: jj@com.dtu.dk
}

Murat Serbay and Werner Rosenkranz Chair of Communications, University of Kiel, Kaiserstr. 2, 24143 Kiel, Germany

\begin{abstract}
We present numerical and experimental investigations of dispersion tolerance for multilevel phase- and amplitude modulation with up to 3 bits per symbol at a symbol rate of 40 Gbaud.
\end{abstract}

\section{INTRODUCTION}

The continous increase in the demand for capacity in optical communication systems has in recent years led to investigations of advanced modulation formats capable of transmitting more than one data bit with each optical pulse. Typically, this is achieved through the use of multiple amplitude levels, multiple phase levels or a combination of the two. This has led to the demonstration of up to 16 symbol states at a symbol rate of 10 Gbaud [1] and up to 8 symbol states at a symbol rate of 40 Gbaud [2].

The motivation for using multilevel modulation formats comes partly from the foreseeable difficulty in designing electronics that can support bit rates higher than $100 \mathrm{Gbit} / \mathrm{s}$, and partly from the fact that many transmission impairments, e.g. dispersion, tend to scale with the symbol rate rather than with the bit rate.

In this paper, measurements and simulations of the dispersion tolerance of various modulation formats with up to 8 symbol states-corresponding to 3 bits per symbol-is presented. In all cases, the symbol rate was 40 Gbaud, i.e. the highest achieved bit rate was $120 \mathrm{Gbit} / \mathrm{s}$. Return to Zero (RZ) pulse shaping was used in all cases. The investigated modulation formats were $40 \mathrm{Gbit} / \mathrm{s}$ On Off Keying (OOK), 40 Gbit/s Differential Binary Phase Shift Keying (DBPSK), 80 Gbit/s Differential Quartenary Phase Shift Keying (DQPSK), $80 \mathrm{Gbit} / \mathrm{s}$ DBPSK ASK and $120 \mathrm{Gbit} / \mathrm{s}$ DQPSK ASK.

\section{SETUP}

A block diagram of the transmitter and receiver used in the experiments is given in figure 1. Continous wave light at $1550 \mathrm{~nm}$ wavelength was converted to a $50 \%$ duty-cycle pulse train by a Mach-Zehnder Modulator (MZM) driven by a $40 \mathrm{GHz}$ sine-wave. A second MZM and a Phase Modulator (PM) provided the phase modulation needed for DBPSK and DQPSK. A third MZM was used for the ASK modulation. All data modulators were driven by a $2^{7}-1$ bits long Pseudo Random Bit Sequence (PRBS) at $40 \mathrm{Gbit} / \mathrm{s}$, thus resulting

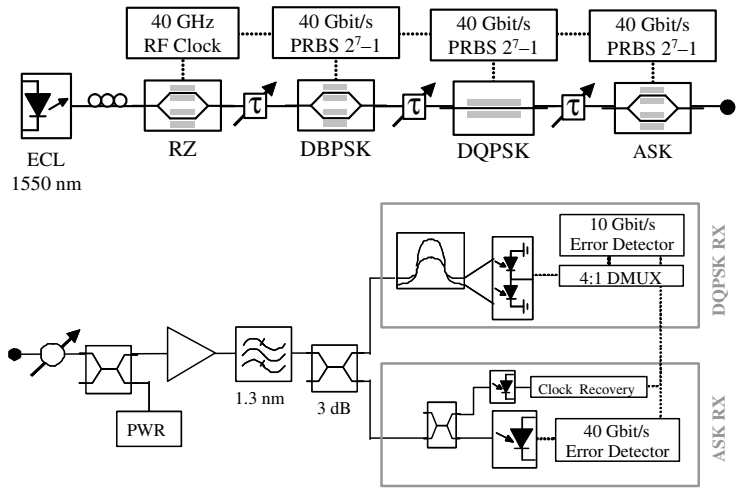

Fig. 1. Block diagram of the RZ-DQPSK-ASK transmitter (top) and receiver (buttom) used in the experiments.

in 120 Gbit/ RZ-DQPSK-ASK. Decorrelation was assured by applying appropriate time delays. By removing one or more of the modulators, RZ-OOK and RZ-DBPSK at $40 \mathrm{Gbit} / \mathrm{s}$, RZ-DBPSK-ASK and RZ-DQPSK at $80 \mathrm{Gbit} / \mathrm{s}$ was achieved. In the combined phase- and amplitude modulated formats, the ASK extinction ratio is a trade-off between good ASK performance and good DB/QPSK performance. The ASKextinction ratio was adjusted to give the same back-to-back receiver sensitivity for the phase- and amplitude modulated signals. For RZ-DBPSK-ASK, $6 \mathrm{~dB}$ was used, and for RZDQPSK-ASK, $4.5 \mathrm{~dB}$ was used.

At the receiver input, the light was attenuated to the desired receiver input power before amplification by an erbium doped fiber amplifier. Out of band spontaneous emission noise was filtered out using an optical band pass filter with a bandwidth of $1.3 \mathrm{~nm}$. After filtering, the signal was split into two by a $3 \mathrm{~dB}$ fiber coupler. One output was used for detection of the ASK modulation via a $40 \mathrm{GHz}$ photodiode and a $40 \mathrm{Gbit} / \mathrm{s}$ error detector, the other output from the fiber coupler was used for the detecection of the phase modulated signal via a onesymbol-delay interferometer and a pair of balanced $40 \mathrm{GHz}$ photodiodes. Due to the lack of a programmable $40 \mathrm{Gbit} / \mathrm{s}$ error detector, the $40 \mathrm{Gbit} / \mathrm{s}$ electrical signal was demultiplexed to four $10 \mathrm{Gbit} / \mathrm{s}$ tributaries. Bit Error Ratio (BER) was 


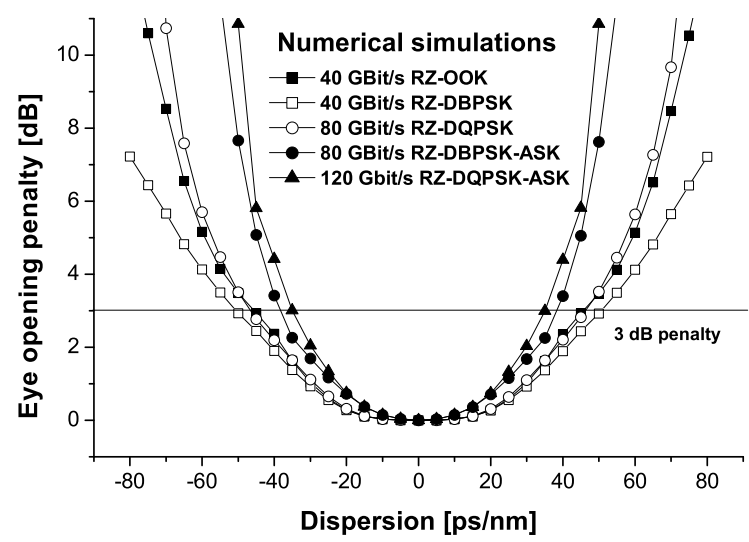

Fig. 2. Numerically simulated dispersion tolerance for the investigated modulation formats.

measured for each of the four tributaries individually. The desired DQPSK tributary was selected by adjustment of the phase-offset in the delay demodulator.

Numerical simulations of the dispersion tolerance of the studied modulation formats has been performed using a model analogue to the setup used for the experiments. RZ pulse shaping with a $50 \%$ duty cycle was used for all the modulation formats. The simulations were performed using an idealized noise free model, where dispersion was introduced as a linear dispersive element. The ASK extinction ratio was optimised to $6 \mathrm{~dB}$ for RZ-ASK-DBPSK and $4.5 \mathrm{~dB}$ for RZ-ASK-DQPSK in order to give equal back to back eye opening for the ASK- and DB/QPSK parts. The signal rise time was $6.25 \mathrm{ps}$, equivalent to $25 \%$ of the symbol period. The quality parameter used throughout the simulations was the Eye Opening Penalty (EOP).

\section{RESULTS AND DISCUSSION}

\section{A. Numerical Simulations}

The results of the numerical simulations are plotted in figure 2. For the RZ-ASK-DBPSK and RZ-ASK-DQPSK graphs, the plotted graph is the ASK part, as this gave the worst performance. From the plot it can be seen that the decrease in dispersion tolerance with increasing number of bits per symbol is very limited. We see that going from $40 \mathrm{Gbit} / \mathrm{s}$ RZ-DBPSK to $80 \mathrm{Gbit} / \mathrm{s}$ RZ-DQPSK results in virtually no penalty, and adding ASK to a phase modulated signal results in a decrease in the $3 \mathrm{~dB}$ penalty limited dispersion tolerance by only $22 \%$.

\section{B. Experimental}

Experimental investigation of the dispersion tolerance of the numerically simulated modulation formats were also performed. The dispersion tolerance was determined by measuring the receiver input power penalty after propagating the signal through various pieces of fiber with different dispersion. Since the quality parameter in the experiments was the BER penalty, some caution should be taken before making a oneto-one comparison with the simulations in which the EOP was

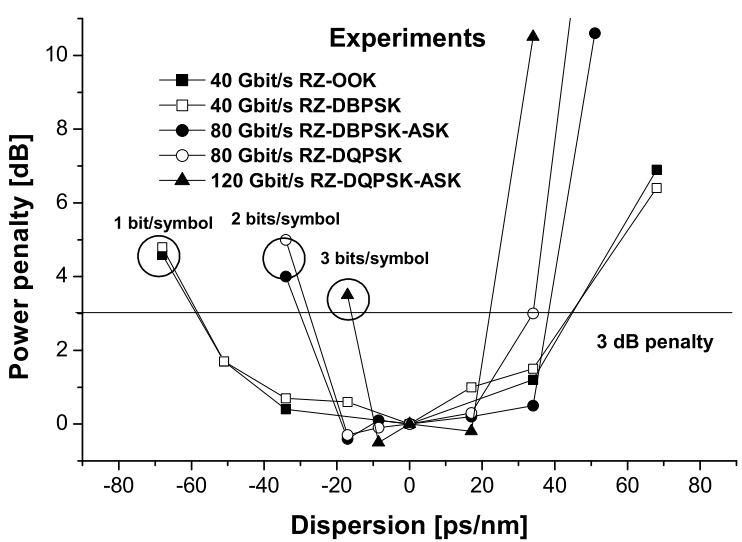

Fig. 3. Measured dispersion tolerance for the investigated modulation formats

used. For each of the investigated modulation formats, the results are plotted in figure 3 . In each case, the plot represents the worst tributary. From the plot, it can be seen that the decrease in dispersion tolerance with increasing number of bits per symbol is worse than suggested by the numerical simulations. We see a reduction in dispersion tolerance by approximately a factor of 2 when doubling the bit rate and by approximately a factor of 3 when tripling the bit rate. This should be compared to the expected behaviour from a binary modulation format, where a doubling of the bit rate would lead to 4 times worse dispersion tolerance $\left(2^{2}=4\right)$ and a tripling would decrease the dispersion tolerance 9 times $\left(3^{2}=9\right)$. It is also observed that in this experiment, the dispersion tolerance for different modulation formats with equal bit- and symbol rate was identical

\section{CONCLUSiOn}

Numerical and experimental investigations of multilevel modulation formats with up to 3 bits per symbol at a symbol rate of 40 Gbaud has been presented. Experiments showed a reduction in dispersion tolerance by approximately a factor of 3 from tripling the bit rate through multilevel modulation, i.e. much better than the 9 times reduction expected from a tripling of the bit rate in a binary modulated system. The numerical simulations showed a potential for even better performance in more ideal systems.

\section{ACKNOWLEDGMENT}

The work descibed was partly funded by the Danish Council for Strategic Research project MultiSpeed, and by COST action 291. ITF Optical Technologies is acknowledged for supplying the delay demodulator.

\section{REFERENCES}

[1] K. Sekine et. al., $40 \mathrm{Gbit} / \mathrm{s}, 16$-ary (4 bit/symbol) optical modulation/demodulation scheme, Electronics Letters, Vol. 41, No. 7, pp. 430 432, March 2005.

[2] T. Tokle et. al., Penalty-free transmission of multilevel $240 \mathrm{Gbit} / \mathrm{s}$ RZ$D Q P S K$-ASK using only $40 \mathrm{GBit} / \mathrm{s}$ equipment, in Proceedings European Conference on Optical Communication, ECOC'05, vol. 6, Glasgow, Scotland, Sept. 2005, paper Th4.1.6, pp. 11-12, post-deadline paper. 